Tudi pri nas je ugotovljena bolezen masarijsko odmiranje platane, ki jo povzroča gliva Splanchnonema platani

\title{
Dušan JURC*
}

V Laboratorij za varstvo gozdov GIS so 14. 6. 2013 iz podjetja Tisa d.o.o. prinesli vzorce vej javorolistne platane (Platanus x hispanica Münch), ki so jih odžagali iz dreves na Kardeljevi ploščadi in na Kongresnem trgu v Ljubljani. Nekatere veje so bile v celoti odmrle in jim je skorja že odstopala, druge pa so imele odmrlo skorjo v vzdolžnih progah. Les pod odmrlimi predeli skorje je spremenil barvo $\mathrm{v}$ temno rjavo do rdečkasto (slika 1 in 2). Povedali so še, da odmirajo platanove veje na enak način tudi na Bratovševi ploščadi v Ljubljani.

Na površini vej, kjer je bila skorja že dlje časa odmrla in je odpadala, so bila razvita številna nespolna trosišča (piknidiji), ki so razpadala in niso vsebovala trosov (slika 3). Pod skorjo na odmrlih vejah so bila tudi množično razvita trosišča, opazili smo jih, ko smo s skalpelom pazljivo odrezali skorjo (slika 4). Zreli piknidiji s trosi so bili razviti samo v skorji, ki je odmrla nedavno in v bližini zdrave skorje (slika 5). V premeru so piknidiji merili od 0,4 do $0,8 \mathrm{~mm}$. Mladi konidiji so bili prosojni, starejši temno rjavi z debelo, bradavičasto steno in običajno $\mathrm{s}$ tremi prečnimi stenami (septami). Merili so $(28,5) 38,5(45,0) \times(12,5) 15,0(16,0) \mu \mathrm{m}$ (slika 6 in 7). Nekateri konidiji so bili obdani s širokim sluzastim ovojem, večina pa ne.

Na osnovi simptomov bolezni ter značilnosti trosišč in trosov smo ugotovili, da je odmiranje skorje javorolistne platane in obarvanje lesa povzročila gliva Macrodiplodiopsis desmazieresii (Mont.) Petr., ki je anamorf (nespolna oblika) glive Splanchnonema platani (Ces.) M.E. Barr (teleomorf).

Za bolezen platan, ki jo povzroča gliva Splanchnonema platani, predlagamo ime masarijsko odmiranje platane, ker sta v Evropi in v Severni Ameriki uveljavljeni imeni massaria disease of plane trees (angl.) in Massaria-Krankheit der Platane (nem.). Ime bolezni izvira iz danes neveljavnega latinskega imena glive (Massaria platani Ces.), vendar je zaradi lažjega iskanja informacij po spletu in komuniciranja $\mathrm{z}$ javnostmi ustrezno, da uporabljamo podobna imena bolezni, kot jih uporablja arboristična stroka drugod.

\section{Opis bolezni in ukrepi}

Gliva Splanchnonema platani, ki je povzročiteljica masarijskega odmiranja platane, povzroča odmiranje skorje platanovih vej, odmiranje celih vej in naglo razgradnjo lesa v okuženih vejah. Zaradi tega se okužene veje pogosto zlomijo in ogrožajo ljudi v urbanih predelih, kjer so platane pomembna drevnina javnih zelenih površin. Bolezen je v Evropi od nekdaj razširjena $\mathrm{v}$ predelih z mediteranskim podnebjem (Italija, Španija), po izjemno močni suši v letu 2003 in v kasnejših letih pa so se poškodbe platan v velikem obsegu pojavile $\mathrm{v}$ Nemčiji (2003), Švici (2005), Avstriji (2007) in Veliki Britaniji (2011). Najpogostejši simptom bolezni so po- dolgovate nekroze skorje in kambija na zgornji površini vej vseh velikosti. Nekroze so najširše pri osnovi veje in običajno obsegajo $20 \%$ do $50 \%$ obsega veje. Dolge so lahko več metrov in proti zunanjemu delu veje se ožijo. Po nastanku začetne nekroze lahko odmre cela veja, pogosteje pa okužena veja ne odmre ampak se odlomi. Značilnost bolezni je namreč razgradnja lesa, podobna mehki/beli trohnobi, ki že v nekaj mesecih po odmrtju veje povzroči njen zlom. Zaradi tega je masarijsko odmiranje platane postalo predvsem velik ekonomski problem v vseh okoljih, kjer se je bolezen pojavila, saj so stroški za kontrolo varnosti dreves in odstranjevanja nevarnih vej $\mathrm{v}$ urbanih nasadih izjemno narasli. Pojav bolezni v centralni in severni Evropi povezujejo $\mathrm{s}$ povišano temperaturo in močnimi sušnimi stresi, ki jih mestno drevje doživlja v zadnjih letih. Vroča in suha poletja oslabijo platane, ki jih rahlo patogena gliva Splanchnonema platani okuži in povzroči odmiranje skorje ter razgradnjo lesa.

Masarijskega odmiranja platane doslej v Sloveniji nismo ugotovili in to poročilo je prva ugotovitev bolezni pri nas. To pomeni, da je treba obvestiti oskrbnike javnih nasadov drevja in lastnike odraslih platan o tej novi bolezni, saj so po informacijah delavcev podjetja Tisa poškodbe platan $\mathrm{v}$ Ljubljani močne. Običajno $\mathrm{v}$ zahodni Evropi svetujejo dva pregleda zdravja drevja v urbanih predelih: enkrat $\mathrm{v}$ rastni sezoni (ko je drevje olistano in se ocenjuje vitalnost ter stanje krošnje) in drugič v obdobju mirovanja (ko se predvsem ugotavljajo okužbe z glivami, ki vplivajo na stabilnost drevesa in povzročajo odlome vej). V obdobjih, ko se po močnih sušah pojavi masarijsko odmiranje platane, pa je treba pregledovati zdravje drevja pogosteje (vsaj trikrat na leto) in ob najdbi bolezni hitro ukrepati (čim hitreje odstraniti okužene veje). Pregled iz tal običajno ni ustrezen za ugotovitev bolezni, ker so spremembe barve okužene skorje in njeno odmiranje (nekroze) pogosto opazne le na zgornji strani vej. Zato je ustrezno, da se krošnjo pregleda s plezanjem ali se uporabi mobilno dvižno košaro.

Opomba: vzorec glive Macrodiplodiopsis desmazieresii (Mont.) Petr. je shranjen v Mikoteki in herbariju Gozdarskega inštituta Slovenije, št. LJF 3365.

\section{Zahvala}

Zahvaljujemo se dr. Leni Marion iz podjetja Tisa d.o.o. za vzorce obolelih platanovih vej.

\section{Viri}

Barr M.E., 1982. On the Pleomassariaceae (Pleosporales) in North America. Mycotaxon 15: 349-383.

Cech T.L., Brandstetter M., Tomiczek C. 2007. Massaria-Krankheit der Platane nun auch in Österreich. Forstschutz Aktuell 40: 26-27. 
Farr, D.F., Rossman, A.Y. 2013. Fungal Databases, Systematic Mycology and Microbiology Laboratory, ARS, USDA. http://nt.ars-grin.gov/fungaldatabases (20.6. 2013)

Keen J. 2013. Tree diseases in London: The economic, social and environmental impact. Special interest paper, City of London Economic Development, 25 str.

http://www.cityoflondon.gov.uk/business/economic-research-andinformation/research-publications/Documents/research-2013/Treediseases-in-London-WebVersion.pdf

Kehr R., Dujesiefken D. 2008. Massaria disease (Splanchnonema platani, Ascomycetes) of plane trees in Germany. Journal of Plant Pathology 90, 2 (Supplement): S2.29.
Kehr R., Krauthausen H.-J. 2004. Erstmaliger Nachweis von Schäden an Platanen (Platanus x hispanica) durch den Pilz Splanchnonema platani in Deutschland. Nachr. Dt. Pflanzenschutzd., 56, 10: 245-251.

*Gozdarski inštitut Slovenije, Večna pot 2, 1000 Ljubljana dušan.jurc@gozdis.si

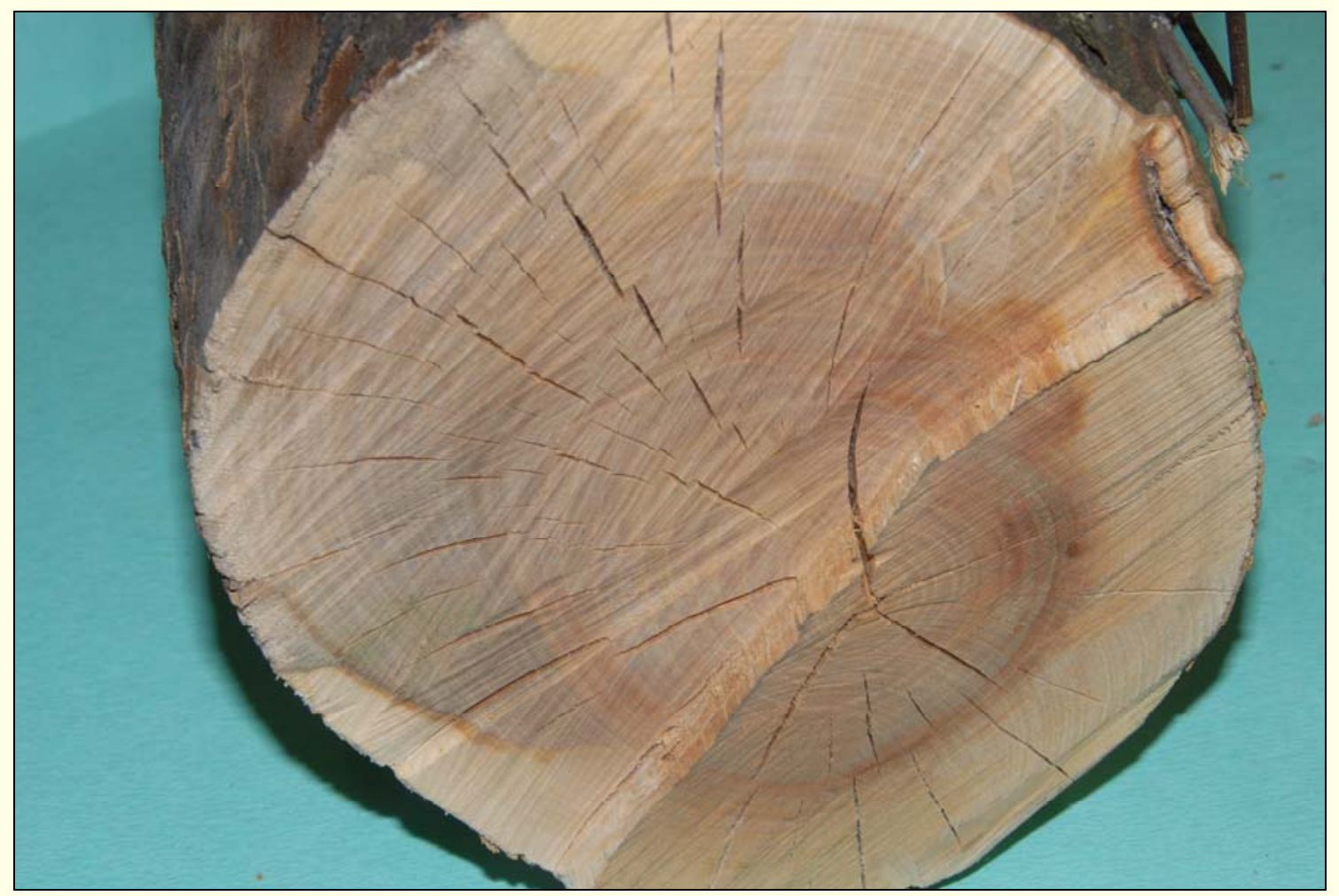

Slika 1: Platanovi veji s premerom $18 \mathrm{~cm}$ je odmrla skorja v progi in les pod odmrlo skorjo se je temneje obarval (Foto: D. Jurc)

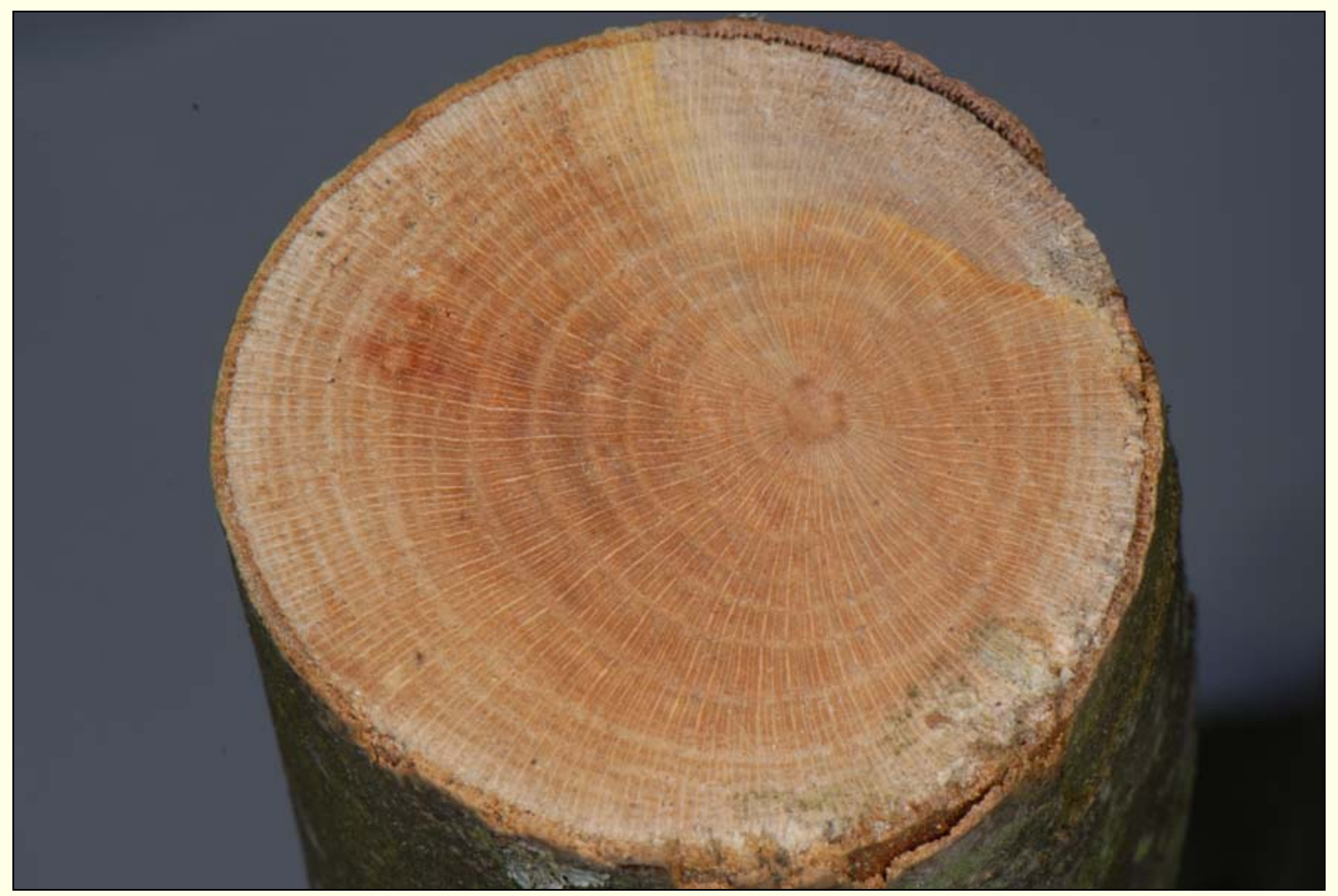

Slika 2: Odmrla tanjša veja in prebarvanje lesa (Foto: D. Jurc) 


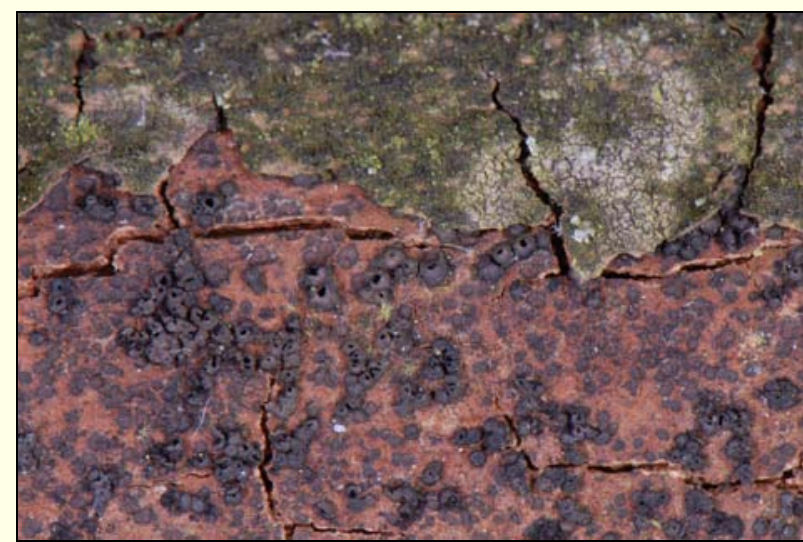

Slika 3: Piknidiji glive Macrodiplodiopsis desmazieresii na površini lesa, kjer je skorja odpadla (Foto: D. Jurc)

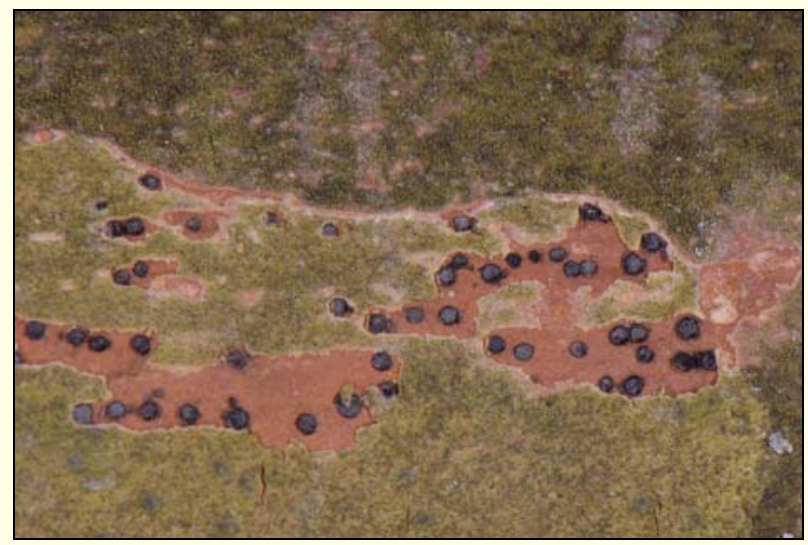

Slika 5: Zreli piknidiji glive Macrodiplodiopsis desmazieresii v nedavno odmrli skorji, ki je bila odstranjena $\mathrm{z}$ ostrim nožem (Foto: D. Jurc)

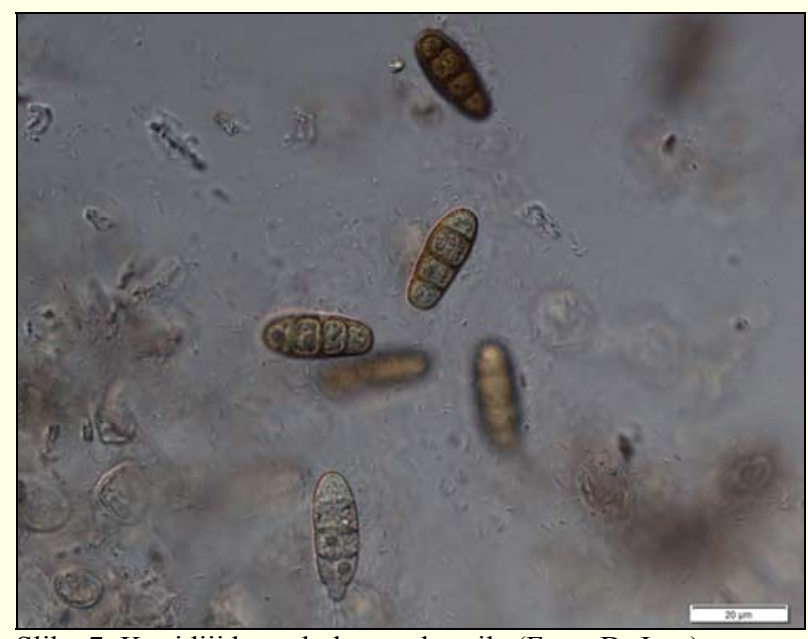

Slika 7: Konidiji brez dodanega barvila (Foto: D. Jurc)

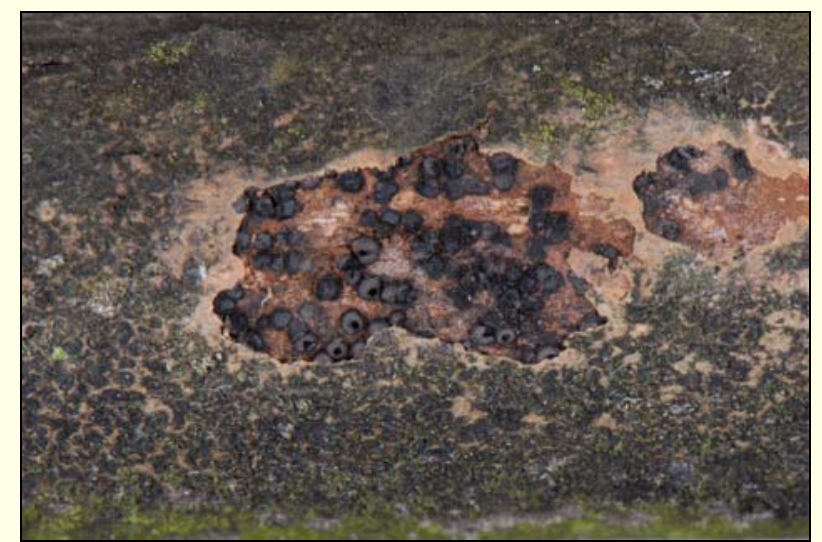

Slika 4: Stari piknidiji pod skorjo (Foto: D. Jurc)

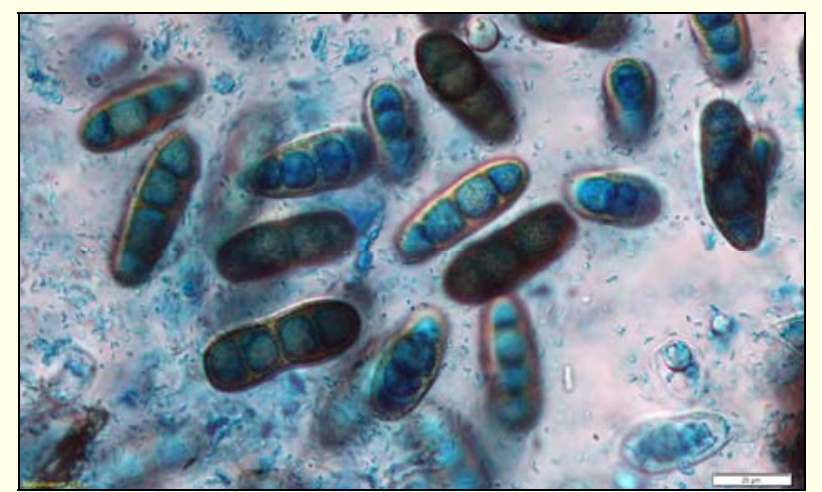

Slika 6: Konidiji glive Macrodiplodiopsis desmazieresii, obarvani z laktofenol - bombažnim modrilom (Foto: D. Jurc) 